\title{
Development and Validation of RP-HPLC Method for Analysis of Rabeprazole Sodium
}

\section{Sumaya Mahmud Sharna ${ }^{1}$, Mehedi Hasan Shuvo ${ }^{1}$, Syef Ferdaus ${ }^{2}$ and Sabiha Chowdhury ${ }^{3}$}

\author{
${ }^{1}$ Department of Pharmacy, Stamford University Bangladesh, 51-Siddeswari Road, Dhaka- 1217, Bangladesh \\ ${ }^{2}$ Department of Pharmacy, State University of Bangladesh, 77 Satmasjid Road, Dhanmondi \\ Dhaka-1205, Bangladesh \\ ${ }^{3}$ Department of Clinical Pharmacy and Pharmacology, Faculty of Pharmacy, University of Dhaka \\ Dhaka-1000, Bangladesh
}

(Received: November 11, 2018; Accepted: January 10, 2019; Published (Web): April 01, 2019)

Rabeprazole sodium, a 4-(3-methoxypropoxy)-3methylpyridinyl derivative of timoprazole, is a proton pump inhibitor that is used for the treatment of acidpeptic diseases, such as duodenal, gastric and esophageal ulceration. ${ }^{1,2}$ A simple, decisive and responsive reverse phase liquid chromatography (RPHPLC) method was developed and validated for assaying rabeprazole sodium. The main purpose of the present study was to establish a relatively simple, single step and inexpensive HPLC method for the determination of rabeprazole sodium in tablet dosage form, since most of the previous methods have been found to be relatively complicated and expensive. This proposed method has been validated as per ICH guidelines. ${ }^{3}$ The developed method has been found to be rapid and sensitive which can be used to determine the potency of rabeprazole sodium in bulk and pharmaceutical dosage form.

Rabeprazole sodium standard was obtained from Department of Pharmacy, Dhaka University. The commercial sample of rabeprazole sodium tablet was purchased from various drug stores. All the chemicals used were of HPLC grade.

A reversed phase waters $\mathrm{C}_{18}(4.6 \times 150 \mathrm{~mm}, 5$ $\mu \mathrm{m})$ column was utilized. For data acquisition and

Correspondence to: Sabiha Chowdhury

E-mail: sabihanabila@gmail.com,

sabiha.nabila@du.ac.bd.; Phone:: 01715691990

Dhaka Un iv. J. Pharm. Sci. 18(1): 127-130, 2019 (June)

DOI: https://doi.org/10.3329/dujps.v18i1.41428 analysis, Empower Pro software was used. Mettler Toledo analytical balance were employed for weighing. The HPLC system consisted of a binary pump (UV visible pump), column heater and UV detector 20 A. For optimum separation, column temperature was maintained at $35^{\circ} \mathrm{C}$ using column oven and isocratic elution with methanol : water (50: $50 ; \mathrm{v} / \mathrm{v}$ ) at the flow rate of $1.0 \mathrm{ml} / \mathrm{min}$. The detection was carried out at $290 \mathrm{~nm}$ whereas injection volume was fixed at $20 \mu \mathrm{L}$. The peak purity was checked with the UV detector (Table 1)

Table 1. Optimized chromatogram.

\begin{tabular}{lc}
\hline Parameter & Values \pm SD \\
\hline Theoretical plates & $390 \pm 10$ \\
USP Tailing Factor (SD) & $0.8 \pm 0.02$ \\
Capacity factor & $2.5 \pm 0.05$ \\
LOD in $\mu \mathrm{g} / \mathrm{ml}$ & 0.369 \\
LOQ in $\mu \mathrm{g} / \mathrm{ml}$ & 4.103 \\
Retention time & $9.99 \pm 0.9$ \\
\hline
\end{tabular}

The mobile phase was prepared with water and methanol at a proportion of 50:50 followed by filtration by using $0.45 \mu$ membrane filters. The standard solution was prepared by adding $100 \mathrm{ml}$ of water to the accurately weighed $100 \mathrm{mg}$ rabeprazole sodium. The concentration of this solution was then adjusted to $10 \mu \mathrm{g} / \mathrm{ml}$. 
According to ICH guidelines, the HPLC method was optimized in terms of precision, accuracy and linearity for the assay of rabeprazole sodium. For method optimization, different column and mobile phase were tried but acceptable retention time, good resolution and theoretical plates were observed only with methanol and water (Figures 1 and 2).

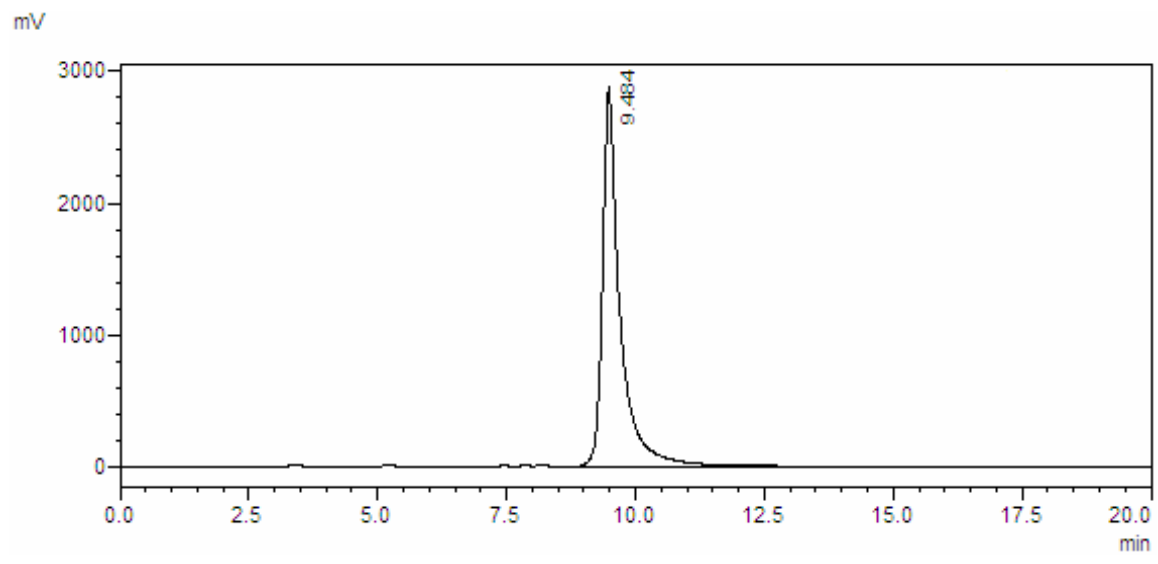

Fig 1. Chromatogram of rabeprazole sodium working standard.

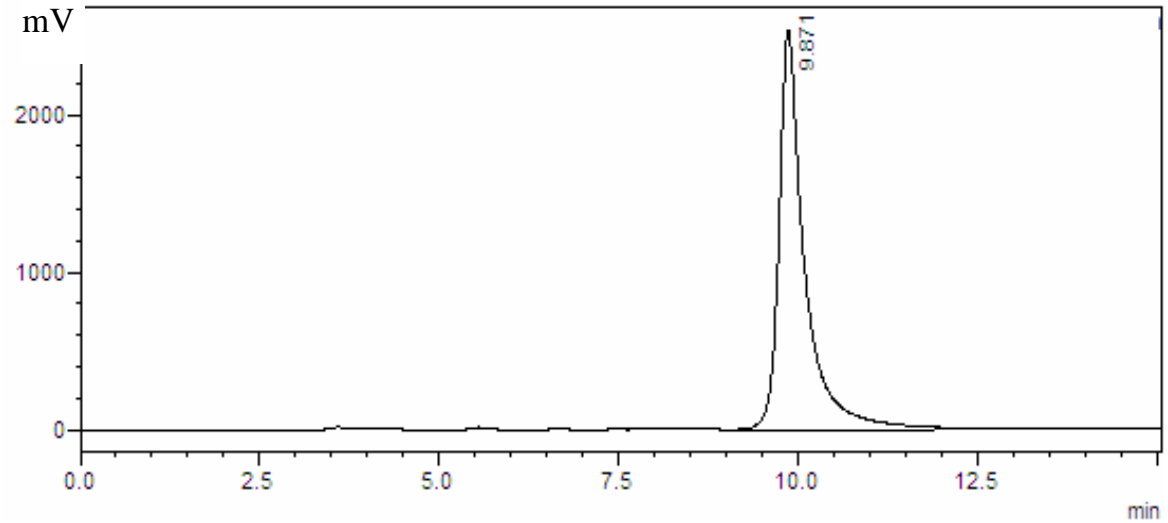

Fig 2. Chromatogram of rabeprazole sodium (sample 3).

It has been observed that rabeprazole with buffer having $\mathrm{pH} 6.8$ gave standard chromatogram. ${ }^{4}$ In this method, the HPLC grade water utilized, had a $\mathrm{pH}$ of $6.8 \pm 0.05$. For this reason, only $(50: 50 \mathrm{v} / \mathrm{v})$ methanol and water were used. This particular method not only produced sharp peak but also provided the easy mobile phase preparation with a flow rate of $1 \mathrm{ml} / \mathrm{min}$ and an acceptable retention time $\left(t_{R}\right)$ of $9.91 \pm 0.9 \mathrm{~min}$, theoretical plates and good resolution of drug. Well defined symmetrical peak was obtained upon measuring the response of eluent under the optimized conditions after thorough experimental trials. Two columns were used for performance investigation, including waters $\mathrm{C}_{18}$ (4.6 $\times 150 \mathrm{~mm}, 5$ micron $)$ and waters $\mathrm{C}_{18}(4.6 \times 250 \mathrm{~mm}$, 5 micron). The UV detector response of rabeprazole sodium was studied and the best wavelength was found to be $290 \mathrm{~nm}$ which showed highest sensitivity.

For the construction of calibration curves, seven calibration standard solutions were prepared over the concentration range. Linearity was determined for rabeprazole sodium in the range of $10-200 \mu \mathrm{g} / \mathrm{ml}$. The correlation coefficient $\left(\mathrm{r}^{2}\right)$ value was $0.99(\mathrm{n}=6)$ and the regression equation for the calibration curve was found to be $\mathrm{y}=450919 \mathrm{x}-1478376$. System suitability test was performed every time before formulation analysis (Table 2). 
Formulation was analyzed as described in experimental section. Assay values were $(100 \pm 8) \%$ for both the formulations. The precision of repeatability was studied by replicate $(n=6)$ analysis of tablet solutions. It was also studied in terms of intra-day changes in peak area of drug solution on the same day and on three different days over a period of one week (Table 3). Accuracy and precision study of the method was calculated by recovery studies at three level by standard addition method (Table 4).

Table 2. System suitability parameters.

\begin{tabular}{llcccc}
\hline SI. No. & Name & Retention time & Area & Theoretical plates & Peak height \\
\hline 1 & Rabeprazole sodium & 9.99 & 87845818 & 400 & 1234567 \\
2 & Rabeprazole sodium & 9.99 & 87569875 & 398 & 1438763 \\
3 & Rabeprazole sodium & 10.01 & 86547985 & 390 & 2034561 \\
4 & Rabeprazole sodium & 9.95 & 88741259 & 410 & 1430781 \\
5 & Rabeprazole sodium & 9.89 & 85214798 & 392 & 1351380 \\
6 & Rabeprazole sodium & 9.92 & 84369871 & 396 & 1256576 \\
AVG & & & 86714.93433 & & \\
SD & & & 1666938.82 & & \\
$\%$ RSD & & 1.9 & & \\
\hline
\end{tabular}

Table 3. Results of potency determination.

\begin{tabular}{cccccc}
\hline SI. No. & Name & Retention time & Area & Injection & Potency \\
\hline 1 & SD & 9.50 & 87845818 & 2 & $99.00 \%$ \\
2 & SD & 9.48 & 87581561 & 2 & $95.77 \%$ \\
3 & Sample 1 & 10.10 & 84898578 & 6 & $99.10 \%$ \\
4 & Sample 2 & 9.70 & 82285678 & 6 & $94.12 \%$ \\
5 & Sample 3 & 9.87 & 87345613 & 6 & $100.25 \%$ \\
6 & Sample 4 & 10.20 & 82245618 & 6 & $94.38 \%$ \\
7 & Sample 5 & 9.90 & 69938034 & 6 & $80.00 \%$ \\
8 & Sample 6 & 10.14 & 62162964 & 6 & $70.56 \%$ \\
9 & Sample 7 & 10.00 & 57719657 & 6 & $66.41 \%$ \\
10 & Sample 8 & 9.92 & 46229825 & 6 & $52.90 \%$ \\
\hline
\end{tabular}

Table 4. Result of precision study.

\begin{tabular}{lccc}
\hline \multirow{2}{*}{ Precision } & \multicolumn{3}{c}{ Estimated amount in percentage } \\
\cline { 2 - 4 } & Injection of each sample $(\mathrm{n}=3)$ & Area & Assay \\
\hline \multirow{2}{*}{ Inter-day } & 1 & 87845818 & $99.00 \%$ \\
& 2 & 82285678 & $94.11 \%$ \\
& 3 & 84785484 & $86.15 \%$ \\
Intra-day & 1 & 87845818 & $99.54 \%$ \\
& 2 & 87654157 & $98.54 \%$ \\
& 3 & 87952479 & $99.54 \%$ \\
\hline
\end{tabular}


Table 5. Result of robustness study.

\begin{tabular}{|c|c|c|c|c|c|}
\hline \multirow[t]{2}{*}{ Parameter } & \multirow[t]{2}{*}{ Level } & \multicolumn{4}{|c|}{ System suitability parameters $(\mathrm{n}=3)$} \\
\hline & & Retention time in minute & Theoretical plates & Capacity factor & Assay ( \%) \\
\hline \multirow{3}{*}{ Flow rate in $\mathrm{ml} / \mathrm{min}$} & 0.5 & 15.87 & $390 \pm 10$ & $2.5 \pm 0.05$ & $96 \%-100 \%$ \\
\hline & 0.8 & 12.98 & & & \\
\hline & 1.0 & 09.99 & & & \\
\hline \multirow[t]{3}{*}{$\%$ of organic solvent } & 40 & 12.05 & $390 \pm 10$ & $2.5 \pm 0.05$ & $96 \%-100 \%$ \\
\hline & 50 & 09.99 & & & \\
\hline & 60 & 03.25 & & & \\
\hline \multirow[t]{3}{*}{$\mathrm{pH}$ of mobile phase } & 4.0 & N/A & $390 \pm 10$ & $2.5 \pm 0.05$ & $96 \%-100 \%$ \\
\hline & 6.8 & 09.99 & & & \\
\hline & 9.2 & 10.20 & & & \\
\hline Columns & $250 \times 4.6$ & 09.99 & $390 \pm 10$ & $2.5 \pm 0.05$ & $96 \%-100 \%$ \\
\hline \multirow[t]{2}{*}{ Wavelength in $\mathrm{nm}$} & 290 & 09.99 & $390 \pm 10$ & $2.5 \pm 0.05$ & $96 \%-100 \%$ \\
\hline & 300 & N/A & & & \\
\hline Column temp. & 35 & 09.99 & $390 \pm 10$ & $2.5 \pm 0.05$ & $96 \%-100 \%$ \\
\hline
\end{tabular}

Rabeprazole sodium is more soluble than rabeprazole. Solubility profile is more important for dissolution and method validation. According to $\mathrm{ICH}$ guidelines, buffer medium in a mobile phase must be compatible with HPLC and compound. As for rabeprazole analysis, $\mathrm{pH}$ optimization was a key factor in proposed method because rabeprazole is rapidly degraded in acidic medium. ${ }^{4}$ Besides, \% of organic solvent is also changed for the validation method.

Robustness was examined by observing the change of small variations in different parameters such as flow rate $( \pm 0.5 \mathrm{ml})$, mobile phase composition $( \pm 20 \%)$, pH of inorganic solvent $( \pm 5.5)$, temperature $\left( \pm 5^{\circ} \mathrm{C}\right)$ and wavelength at $300 \mathrm{~nm}$ and $290 \mathrm{~nm}$ (Table 5).

In conclusion, the proposed method makes use of fewer amount of solvents and changed a set of conditions that required a short time. So the method developed here can therefore be used for routine analysis of rabeprazole sodium in bulk and its tablet dosage forms. It does not suffer from any interference due to common excipients present in pharmaceutical preparation and thus can be conveniently adopted for quality control analysis.

\section{REFERENCES}

1. https://pubchem.ncbi.nlm.nih.gov/compound/rabeprazole \#section=Top. Accessed on 10 September, 2018.

2. Robinson, M. and Horn, J. 2003. Clinical pharmacology of proton pump inhibitors: what the practising physician needs to know. Drugs 63, 2739-54.

3. International Conference on Harmonization. 2005. Validation of analytical procedures: Text and methodology, Q2 (R1). IFPMA, Geneva, Switzerland.

4. Sharma, R, Mishra, G. P. and Charturvedi, S,C. 2010. Development and validation of RP-HPLC method for the simultaneous determination of rabeprazole sodium and itopride hydrochloride in solid dosage form. ISSN: $0973-$ 4945, E-Journal of Chemistry 7, 947-953. 